\title{
Enhanced resistance to the cellulose biosynthetic inhibitors, thaxtomin A and isoxaben in Arabidopsis thaliana mutants, also provides specific co-resistance to the auxin transport inhibitor, 1-NPA
}

\author{
Robert S Tegg ${ }^{1 *}$, Sergey N Shabala², Tracey A Cuin², Noel W Davies ${ }^{3}$ and Calum R Wilson ${ }^{1,2}$
}

\begin{abstract}
Background: Thaxtomin A (TA) is a phytotoxin produced by plant pathogenic Streptomyces spp. responsible for potato common scab. TA inhibits cellulose biosynthesis in expanding plant tissues and is essential for disease induction. Auxin treatment of various plant tissues has been repeatedly demonstrated to inhibit TA toxicity and to reduce common scab. This work utilises Arabidopsis thaliana mutants with resistance to cellulose biosynthesis inhibitors (CBIs) to investigate the interaction between TA, other CBls and auxins.

Results: Three CBI resistant $A$. thaliana mutants; txr1-1 (tolerance to TA), ixr1-1 (tolerance to isoxaben - IXB) and KOR1 (cellulose deficiency), showed no altered root growth response to treatment with natural or synthetic auxins, nor with the auxin efflux transport inhibitor 2,3,5-Triiodobenzoic acid (TIBA). However, all mutants had significantly enhanced tolerance to 1-napthylphthalamic acid (NPA), another auxin efflux transport inhibitor, which blocks polar auxin transport at a site distinct from TIBA. NPA tolerance of txr1-1 and ixr1-1 was further supported by electrophysiological analysis of net $\mathrm{H}^{+}$fluxes in the mature, but not elongation zone of roots. All three mutants showed increased tolerance to IXB, but only txr1-1 showed tolerance to TA. No mutant showed enhanced tolerance to a third CBI, dichlobenil (DCB).

Conclusions: We have demonstrated that plant tolerance to TA and IXB, as well as cell wall synthesis modifications in roots, have resulted in specific co-resistance to NPA but not TIBA. This suggests that CBI resistance has an impact on polar auxin efflux transport processes associated with the NPA binding protein. We also show that NPA inhibitory response in roots occurs in the mature root zone but not the elongation zone. Responses of mutants to CBls indicate a similar, but not identical mode of action of TA and IXB, in contrast to DCB.
\end{abstract}

Keywords: 1-napthylphthalamic acid - NPA, 2,3,5-Triiodobenzoic acid - TIBA, Thaxtomin A, Isoxaben, Dichlobenil, Cellulose biosynthetic inhibitor, Common scab, Ion fluxes, Plasma membrane

\footnotetext{
*Correspondence: Robert.Tegg@utas.edu.au

${ }^{1}$ Tasmanian Institute of Agriculture (TIA), University of Tasmania (UTAS),

13 St John's Ave, New Town, Tasmania 7008, Australia

Full list of author information is available at the end of the article
} 


\section{Background}

Thaxtomin A (TA) is the major phytotoxin produced by pathogenic Streptomyces spp. responsible for common scab, a globally important disease of potato [1]. TA inhibits cellulose biosynthesis in expanding plant tissues and its production is essential for disease induction [2-4]. Based on similarity of symptoms produced, TA is believed to be closely related to other cellulose biosynthesis inhibitors (CBIs) such as isoxaben (IXB) and dichlobenil (DCB) [5]. The linkage of the modes of actions of these compounds has been confirmed with habituation studies to TA, revealing cross-resistance to both IXB and DCB [6], although mechanisms of resistance were not investigated.

The cellular target of TA has not been identified $[6,7]$. This is in contrast to IXB, where mutant analyses have identified specific cellulose synthase (CesA) complexes (CesA3 and CesA6) from the plasma membrane as toxin targets $[8,9]$. Putative cellular targets for DCB have also been indirectly identified and include CesA 1 or CesA 5 and other regulatory proteins [10,11]. A recent study showing similar genes were upregulated following TA and IXB treatments of $A$. thaliana cells suggested a possible linkage in activity between these two CBI's [12]. An initial interaction between TA and the plant cell membrane, resulting in ion flux signaling has been reported [13], as has induction of programmed cell death [14]. However, little is known about the exact mechanism of cellular toxicity of TA. The TXR1 gene is involved in a cellular transport system and mutations in this gene in Arabidopsis thaliana txr1-1 lead to a decrease in toxin sensitivity, most likely due to reduced toxin uptake [15].

In prior studies we have demonstrated an inverse association between TA toxicity and auxin or auxin-like compounds $[13,16,17]$. Foliar treatment of potato plants with auxin and auxin-like compounds has been shown to suppress common scab development $[17,18]$. Work in our laboratory has provided evidence that the mechanism of disease suppression is due to auxins inhibiting TA toxicity $[16,17]$. This and other electrophysiological data, whereby an auxin sensitive A. thaliana mutant (ucu2-2 and gi2) showed increased sensitivity to TA [13] further support the link between auxin and TA toxicity. However, other researchers [12] have questioned the direct causal relationship between TA and auxin itself as they noted very few auxin genes were upregulated in response to TA. Thus, the interaction between auxin and TA remain elusive.

Utilising CBI resistant $A$. thaliana mutants that are well characterized may provide an important resource for delineating and understanding disease resistance pathways and mechanisms of action and interactions [19]. In the case of TA, a resistant mutant txr1-1 has been described [15] as has an IXB resistant mutant ixr1-1 [20] and a loss-of function mutant in genes required for cell wall synthesis KORRIGAN (KOR1) [21,22]. These mutants and others may play a role in delineating similarities and differences in reaction to CBIs and auxinic compounds and serve as useful tools in defining further interactions between TA and associated compounds.

In this work, we investigate the unique interaction of TA toxicity and its amelioration by auxin. We demonstrate that the interaction is not a direct effect of auxin per se, but is rather mediated through an interaction with polar auxin transport, associated with the NPA binding protein of the efflux carrier. Further, responses of key mutants indicate a probable commonality in mode of action of both IXB and TA, distinct from DCB which appears to be more distantly related.

\section{Results}

\section{Mutant screening against various auxin sources}

Consistent with previous studies [23], aux1-7 had enhanced resistance to both 2,4-D $(P=0.0004, F=15.6)$ and IAA $(P<0.0001, F=35.4)$, but not to NAA $(P=0.81$, $F=0.06)$, when compared to $\mathrm{RG}_{50}$ value of the WT control (Figure 1). The TA resistant line txr1-1 $(P=0.32$ $0.85, F=0.04-1.02)$, ixr1-1 $(P=0.78-0.93, F=0.01-0.08)$ and KOR1 $(P=0.56-0.95, F=0.01-0.56)$ all showed sensitivity to all three auxins equivalent to the WT control (Figure 1).

\section{Mutants with altered response to auxin transport inhibitors}

All three A. thaliana CBI mutants examined (ixr1-1, txr1-1, KOR1) showed enhanced root-based resistance to the auxin transport inhibitor, NPA, in comparison to the WT (Figure 2A). Concentration levels of NPA required to inhibit root growth by $50 \%\left(\mathrm{RG}_{50}\right)$ were approximately 13-fold (ixr1-1; $\mathrm{RG}_{50}: 27.1 \mu \mathrm{M} ; P<0.0001, F=25.2$ ), 3.5-fold (txr1-1; RG $\mathrm{R}_{50}: 7.08 \mu \mathrm{M} ; P=0.0005, F=14.5$ ) and 1.5-fold (KOR1; $3.07 \mu \mathrm{M}, P=0.047, F=4.2$ ) higher than the WT $\left(\mathrm{RG}_{50}: 2.04 \mu \mathrm{M}\right)$. The response of $a u x 1-7$ was no different to the WT $(P=0.94, F=0.01)$. In contrast, all mutant lines and the WT control examined showed equivalent root growth suppression when treated with various concentrations of the auxin transport inhibitor, TIBA (Figure 2B).

\section{Root ion fluxes after pretreatment with auxin transport inhibitor, NPA}

No differences between $A$. thaliana genotypes were revealed in analyses of net $\mathrm{H}^{+}$fluxes in the root elongation zone in response to NPA; all plants showed net $\mathrm{H}^{+}$uptake of 10 to $16 \mathrm{nmol} \mathrm{m}^{-2} \mathrm{~s}^{-1}$, not significantly different to the untreated control (Figure 3A). In the mature root zone, lower net $\mathrm{H}^{+}$uptake $\left(0.5\right.$ to $\left.5 \mathrm{nmol} \mathrm{m}^{-2} \mathrm{~s}^{-1}\right)$ was recorded across all genotypes. In contrast to elongation 

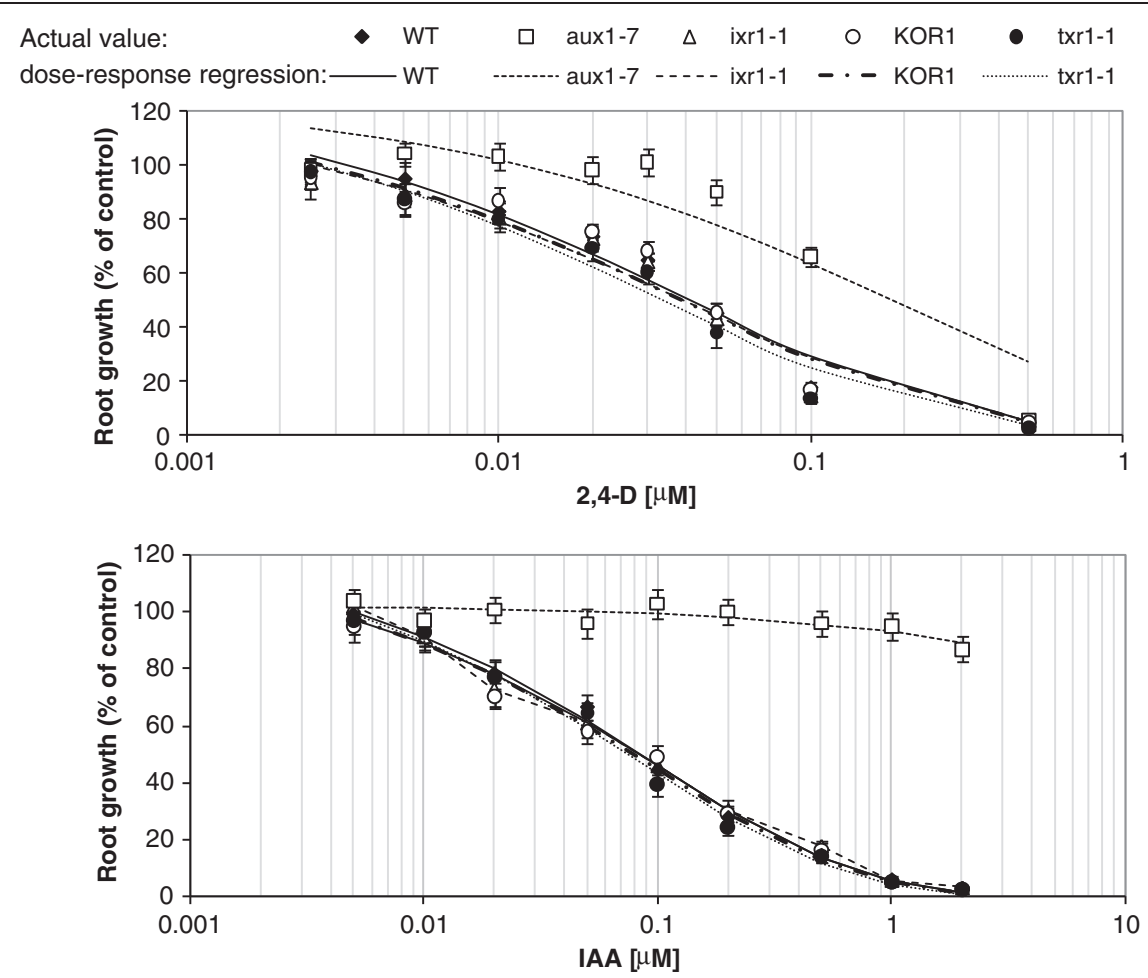

B



Figure 1 Root growth suppression of Arabidopsis lines in response to auxin treatment. Wild type and mutant Arabidopsis thaliana seedlings were treated for $72 \mathrm{~h}$ on medium containing: (A) 2,4-D; (B) IAA; (C) NAA. Individual data points are expressed as mean percentages \pm SE $(n=20)$ of control root growth on medium with no auxin applied.

zone, NPA induced a significant reduction in net $\mathrm{H}^{+}$uptake, in WT $(P<0.05)$, but not in the CBI resistant mutants (ixr1-1, txr1-1) (Figure 3B).

\section{Mutants with differential response to $\mathrm{CBls}$}

Root growth rates in the $A$. thaliana lines tested varied between 5 and $9 \mathrm{~mm} \mathrm{day}^{-1}$ (depending on genotype) under control conditions where no toxin was applied (data not shown). Root growth patterns in response to DCB were consistent across all five genotypes tested with $R_{50}$ values not significantly different compared to the control WT genotype (Figure 4A).

In response to IXB, the three CBI mutants showed enhanced tolerance with aux 1-7 responding no differently to the WT (Figure 4B). The magnitude of enhanced tolerance varied with $i x r 1-1$, txr1-1 and KOR1 having approximately 10 -fold $(P<0.0001, F=26.3)$, 4-fold $(P=0.0004$, $F=15.2)$ and 1.8 -fold $(P=0.04, F=4.8)$ greater tolerance respectively to IXB, than the WT.

Root growth rates for each line decreased with increasing TA concentrations (Figure 4C), with other typical symptoms including hypertrophy, necrosis and chlorosis [15,17,24] also observed. As expected [15], in the presence of TA, the txr1-1 mutant had a significantly greater root growth rate $\left(\mathrm{RG}_{50}\right.$ of $0.20 \mu \mathrm{M} ; P<0.0001$, $F=24.5)$ than the WT $\left(\mathrm{RG}_{50}\right.$ of $\left.0.073 \mu \mathrm{M}\right)$. No other mutant had TA tolerance different to the WT (aux1-7, $P=0.92, F=0.01 ; i x r 1-1, P=0.77, F=0.09$, and $K O R 1$, $P=0.85, F=0.03$ ) (Figure 4C). 




A

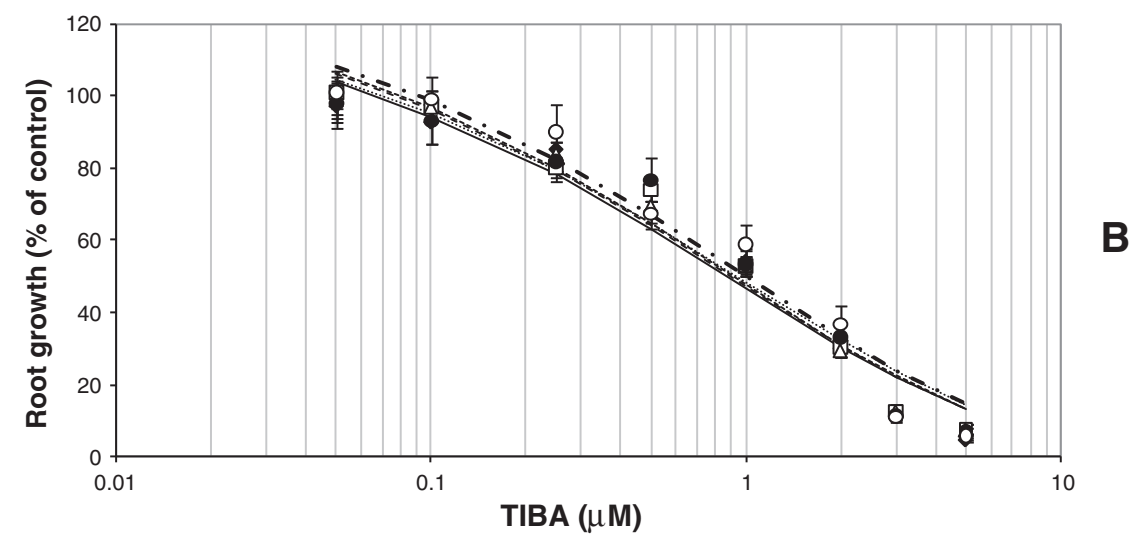

Figure 2 Impact of auxin transport inhibitors on root growth of Arabidopsis lines. Wild type and mutant Arabidopsis thaliana seedlings were treated for $72 \mathrm{~h}$ on medium containing: (A) 1-napthylphthalamic acid - NPA, or (B) 2,3,5-Triiodobenzoic acid - TIBA. Individual data points are expressed as mean percentages $\pm \mathrm{SE}(n=20)$ of control root growth on medium with no exogenous auxin transport inhibitors applied.

\section{Quantification of CBI levels in root tissue after CBI and NPA treatment}

Consistent with previous studies [15], $\operatorname{txr} 1-1$ was the only mutant to accumulate significantly $(P<0.05,4$-fold $)$ less TA than all other lines tested; with the addition of NPA in combination with TA producing the same result (Table 1). IXB quantification from the root tissue showed some variation although there were no significant differences produced across the lines tested with or without NPA treatment. The line $\operatorname{txr} 1-1$ showed the lowest levels of detection (Table 1).

\section{Discussion}

The auxin: thaxtomin interaction - auxin may not be directly related with resistance to $\mathrm{CBIs}$

Our previous studies with IAA and NAA in A. thaliana $[13,17]$ and with $2,4-D$ in potato [17] demonstrated a negative association between TA toxicity and auxin content of treatment medium or concentration within plant tissues. However, the specific nature of this association is not known. Recent transcriptional profiling studies in response to both TA and IXB showed few auxinresponsive genes were upregulated by these CBIs and the authors argued that these compounds do not act on auxin receptors [12]. Additionally, Errakhi and colleagues [25] found that addition of IAA had no effect on TA induced electrophysiological $\mathrm{H}^{+}$changes in Arabidopsis, and suggested that TA and IAA do not interact at this level. Supporting these findings we show that the root growth response of three CBI $A$. thaliana mutants (ixr1-1, KOR1, txr1-1) was not altered by any of the three auxins $(2,4-\mathrm{D}$, IAA and NAA). This suggests that common mechanisms that confer resistance in these mutants: ixr1-1 - altered specific cellulose synthase (CesA) complexes [8,9,26]; KOR1 - cellulose deficiency [21,22,27]; txr1-1 - altered cellulose synthesis activity $[7,15]$; does not influence auxin uptake and associated root growth response, suggesting no direct $\mathrm{CBI}$ - auxin interaction.

\section{Linkage between auxin transport and resistance to CBls} Whilst no direct CBI - auxin interaction could be identified in this study or by others [12,25] Duval and 

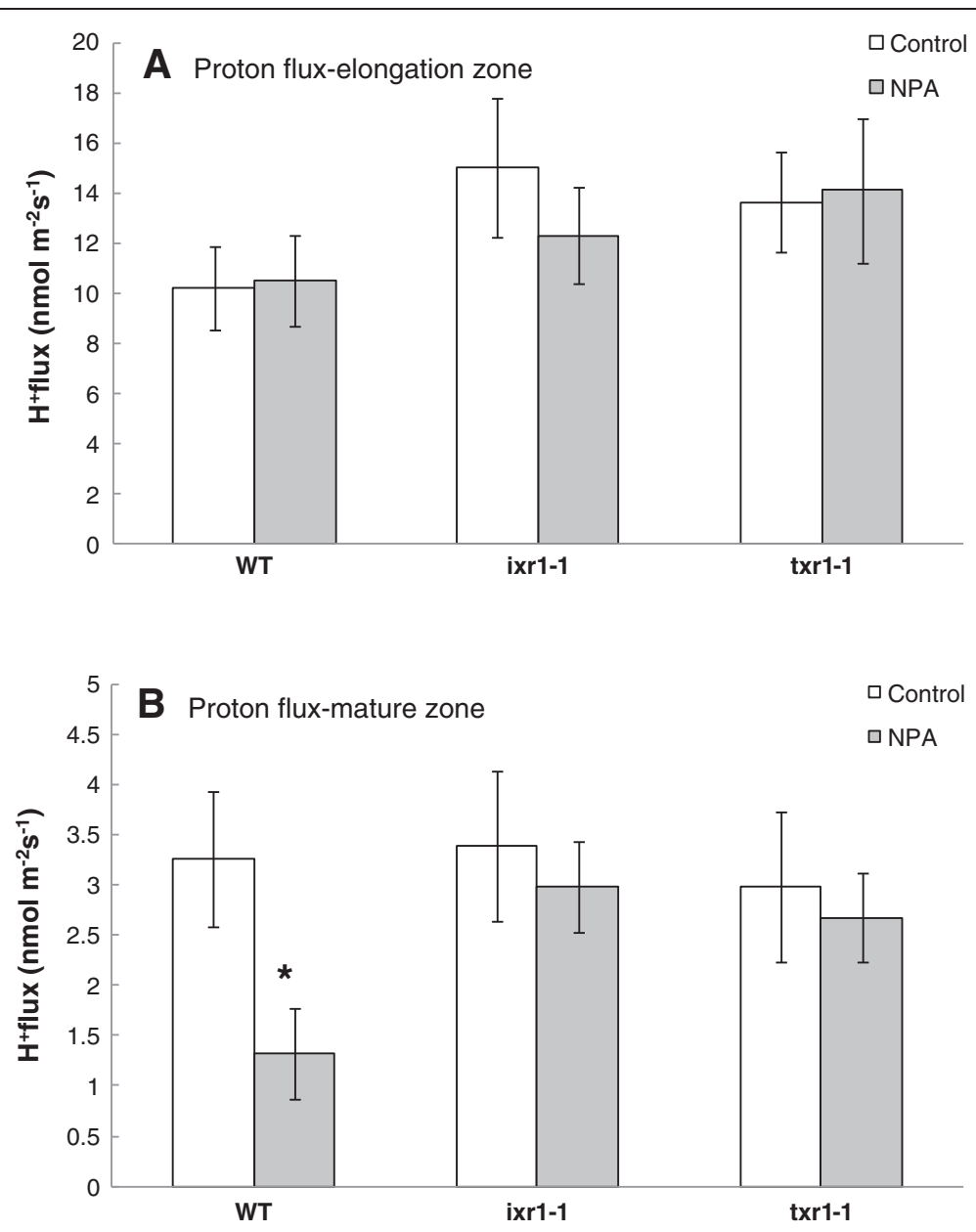

Figure $3 \mathrm{Net}^{+}$fluxes from various root zones of Arabidopsis lines treated with auxin transport inhibitor NPA. Measurements were taken from the elongation (A) and mature (B) root zone of Arabidopsis thaliana plants after $24 \mathrm{~h}$ of treatment with NPA. Mean \pm SE $(n=8)$. The flux convention is "influx positive". * significantly different from the control of that genotype (*P $<0.05, \mathrm{t}$ test).

Beaudoin [12] found that the PINOID-BINDING protein (PBP1) gene and the TOUCH3 gene (TCH3) that both bind to PINOID (PID) were upregulated in response to both IXB and TA. PID is a protein kinase that acts as a positive regulator of auxin efflux polar transport [28]. Whilst this suggested a link between inhibition of cellulose synthesis and auxin transport, more definitive proof was required [12]. Our results presented here make use of $A$. thaliana mutants which provide an important resource for delineating and understanding disease resistance pathways and mechanisms of action [19]. In this case modifications in cellulose biosynthesis, expressed in A. thaliana mutants, provide a link between auxin transport and inhibition of cellulose synthesis.

\section{Differential response of $A$. thaliana CBI mutants to two} key auxin transport inhibitors

The resistance of three mutants with altered cellulose synthesis properties (ixr1-1, KOR1, txr1-1) to NPA implies a probable interaction between cellulose synthesis and this auxin transport efflux inhibitor. The specificity of this interaction was demonstrated by the finding that none of these mutants had an enhanced resistance to a second auxin efflux inhibitor, TIBA, that has a cellular binding site distinct to NPA $[29,30]$.

Neither auxin efflux carrier sites nor the mode of action of inhibitors acting on these sites are fully understood [29,31] with the complexities of auxin transport and carriers constantly evolving [32-34]. However, NPA functions as a general inhibitor of secretory processes (by binding to a putative NPA-binding protein), associated with the auxin efflux carrier site $[31,35]$. TIBA by contrast has its binding site directly associated with the auxin efflux carrier site [30] distinct from the putative NPA-binding protein [35]. It is important to note that auxin transport and binding studies indicate that all types of auxin transport inhibitors act at a site distinct from that of the auxin binding site on the efflux carrier, 


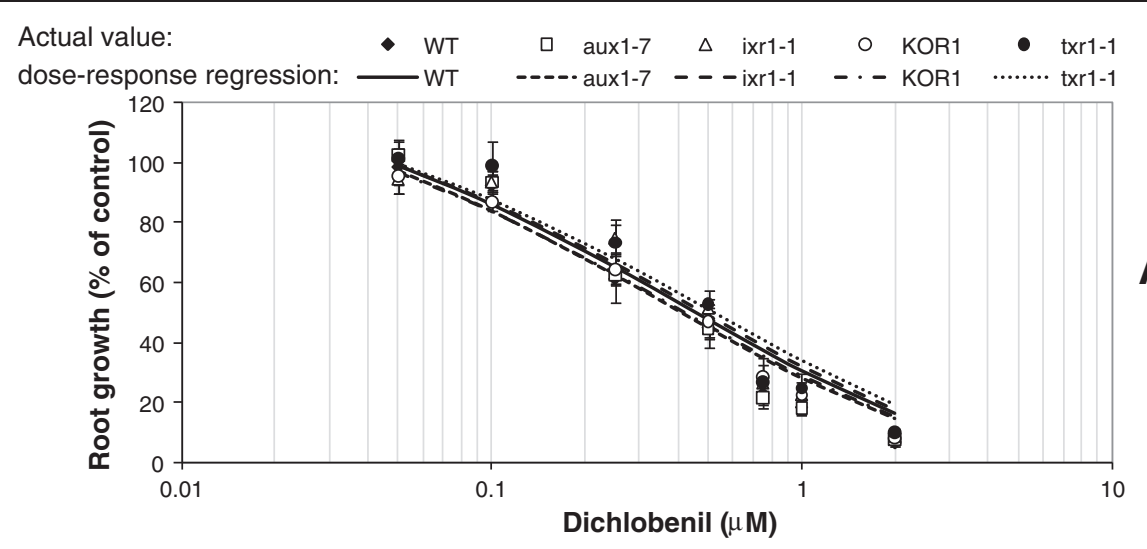

A

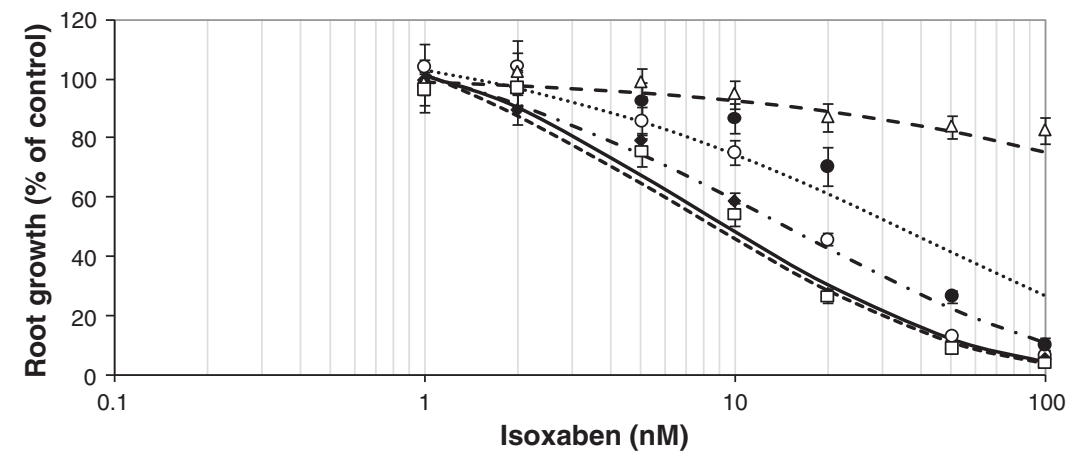

B

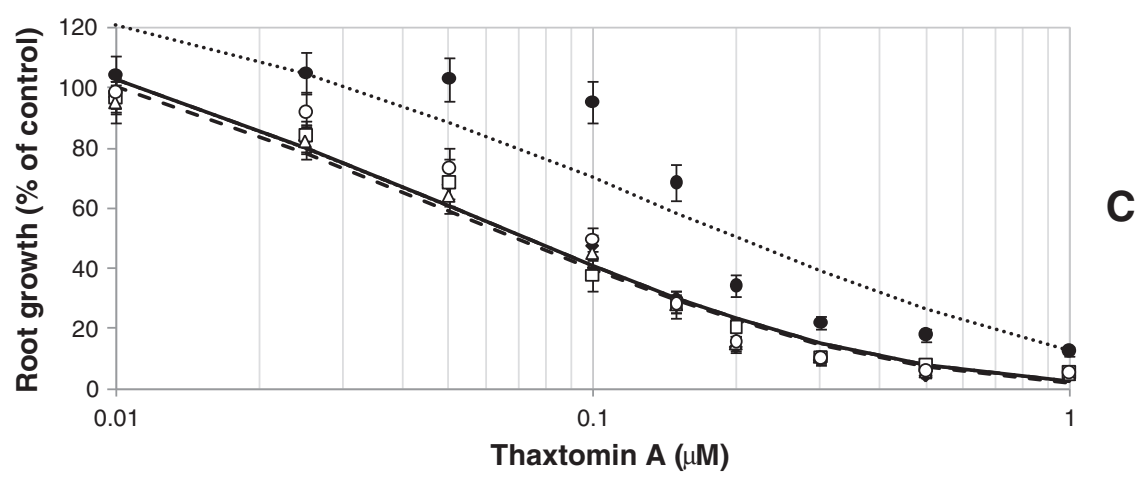

Figure 4 Root growth suppression of Arabidopsis lines in response to cellulose biosynthetic inhibitor treatment. Wild type and mutant Arabidopsis thaliana seedlings were treated for $72 \mathrm{~h}$ on medium containing (A) Dichlobenil; (B) Isoxaben, or (C) Thaxtomin A. Individual data points are expressed as mean percentages \pm SE $(n=20)$ of control root growth on medium with no exogenous cellulose biosynthetic inhibitors applied.

i.e. they are non-competitive with auxins [30]. Taken together with the lack of any response to auxin source in all three CBI mutants, it suggests that these mutations associated with cellulose synthesis also invoke a modified response to specific compounds inhibiting polar auxin transport, i.e. NPA, rather than auxin itself, and suggests that the CBI-auxin interaction may be linked to indirect processes associated with NPA-specific binding to the auxin efflux carrier.

The NPA resistance of the ixr1-1 and txr1-1 mutant in our study was 13 and 3.5-fold greater than wild-type, respectively, but the nature of the NPA resistance is unknown. The finding of NPA resistance in these two CBI mutants has not previously been reported. These mutants represent a useful research tool in furthering the understanding of NPA-binding [36], cellulose biosynthesis and all its complexities.

It must be stated that the usage of NPA in these studies does have some limitations. These include the fact that NPA has a complex mode of action that is not specific for auxin transport but a general inhibitor of secretory processes $[31,35]$. Additionally, NPA may target different proteins and transporters at different concentrations $[32,33]$. 
Table 1 Quantification of thaxtomin A and isoxaben from A. thaliana root tissue ${ }^{1}$

\begin{tabular}{|c|c|c|c|c|}
\hline \multirow{2}{*}{$\begin{array}{l}\text { A. thaliana } \\
\text { line }\end{array}$} & \multicolumn{2}{|c|}{ Thaxtomin A (ng g $\left.{ }^{-1} \mathrm{FW}\right)$} & \multicolumn{2}{|c|}{ Isoxaben (ng g $\left.{ }^{-1} \mathrm{FW}\right)$} \\
\hline & $-N P A$ & $+\mathrm{NPA}$ & $-N P A$ & $+\mathrm{NPA}$ \\
\hline$\overline{W T}$ & $154 \pm 23^{b}$ & $135 \pm 25^{b}$ & $45 \pm 15$ & $37 \pm 18$ \\
\hline aux1-7 & $143 \pm 21^{b}$ & $126 \pm 27^{b}$ & $49 \pm 26$ & $43 \pm 19$ \\
\hline ixr1-1 & $176 \pm 26^{\mathrm{b}}$ & $144 \pm 19^{b}$ & $30 \pm 14$ & $32 \pm 16$ \\
\hline KOR1 & $130 \pm 29^{b}$ & $112 \pm 23^{b}$ & $31 \pm 14$ & $29 \pm 15$ \\
\hline $\operatorname{txr} 1-1$ & $44 \pm 15^{\mathrm{a}}$ & $40 \pm 15^{\mathrm{a}}$ & $27 \pm 12$ & $27 \pm 13$ \\
\hline
\end{tabular}

${ }^{1}$ thaxtomin $\mathrm{A}$ and isoxaben levels from root tissue were quantified after $24 \mathrm{~h}$ on treatment media which contained either $1 \mu \mathrm{M}$ thaxtomin $\mathrm{A} \pm 3 \mu \mathrm{M} \mathrm{NPA}$; or $100 \mathrm{nM}$ isoxaben $\pm 3 \mu \mathrm{M}$ NPA. Results are the means $\pm \mathrm{SE}$ of three replicates. a, bStatistically different values $(t$-test, $\mathrm{P}<0.05)$ are indicated with a different letter in each column.

Auxin transport inhibitor, NPA affects ionic homeostasis in the mature but not elongation root zone

In the WT line, NPA treatment effects on proton flux were observed in the mature but not the elongation root zone. The suppression of $\mathrm{H}^{+}$fluxes in the mature root zone mirrors the root growth suppression patterns of the three genotypes studied. The reduction in $\mathrm{H}^{+}$flux may be attributed to a cessation of normal growth type responses as occurs in response to a toxin [13] or foreign compound [37]. That the major response occurred in the mature but not elongation zone was unexpected, given the well-established role of auxin in control over cell division in the root apex [38] and indicates a different mode of action. It is possible that NPA is partially suppressing the polar transport of endogenous auxin from the root apex into the mature zone, so affecting normal growth processes and flux dynamics in this mature region. In this assay, NPA tolerance was again demonstrated in CBI resistant mutants ixr1-1 and txr1-1. These results further support the link between inhibition of cellulose synthesis and the auxin efflux transport processes influenced by NPA.

\section{Uptake of CBI's not affected by NPA presence}

To determine a possible interaction between CBI and NPA resistance the uptake of the two toxins, TA and IXB was monitored across the mutant lines. The conclusion from these quantitative assays was that NPA did not affect CBI uptake suggesting no direct interaction between these compounds. It must be stated that this work is only preliminary in nature and that the presence of auxin compounds themselves may have a greater impact on CBI uptake as this has been previously demonstrated $[16,17]$, hence further investigation on CBI uptake with presence of auxin sources is warranted. Nonetheless, the new methodologies presented here confirm previous findings that txr1-1 has an altered transport component that reduces TA uptake [15] and therefore less compound accumulated in the root tissue.

\section{Mutants with differential responses to $\mathrm{CBIs}$}

Testing CBI A. thaliana mutants as presented here or in other plant cell systems such as habituated poplar cell suspensions with resistance to CBIs [6] can aid in identifying common mechanisms across toxins [19,39] and similarities in resistance mechanisms of the mutants. Better understanding of these complexities will enable a greater understanding of how plant cells respond to toxins and key information about cellulose synthesis [6]. Indeed, similarity of responses expressed in this study particularly by $\operatorname{txr} 1-1$ and $i x r 1-1$, with enhanced multiple resistances to both IXB and NPA suggests that TA and IXB share a common mode of action. It is known that txr1-1 lacks a TXR1 gene product, with the product suspected to be involved in a transport system [15]. Therefore, it is probable that both IXB and NPA may utilise this transport system in some manner. In contrast, the ixr1-1 mutant, with an altered component of a cellulose synthase gene [9], did not show resistance to TA. The lack of cross-resistance of ixr1-1 to TA, observed in this study suggests that this altered target enzyme is not a target of TA [12].

\section{TA is closely associated with IXB but more distantly with DCB}

Previous research indicated a commonality in mode of action between TA and IXB, with both inhibiting cellulose synthesis $[7,26]$, initiating a programmed cell death response [14] and upregulating a similar set of genes when applied to $A$. thaliana suspension cells [12]. Whilst we found that txr1-1, ixr1-1 and KOR1 had enhanced resistance to IXB and NPA, none of these mutants had altered resistance to DCB. Based on our complementary results from three different mutants it appears that TA is closely linked to IXB but more distantly related to DCB [12].

\section{Conclusions}

Whilst the mode of action and specific target of TA have not yet been identified [6] data presented here are suggestive of a direct linkage between auxin efflux transport processes that may be inhibited by NPA and inhibition of cellulose biosynthesis. The MIFE ion flux data highlights an important role of the mature root zone as yet another target for possible auxin-TA interaction and provides an electrophysiological insight into these unique CBI's. The usage of well characterized Arabidopsis mutants enabled associations between toxin mode of actions to be identified with IXB and TA linked, compared to the more distantly related CBI, DCB. Further work in elucidating mechanisms is required but the identification of strong resistance to NPA expressed by both ixr1-1 and txr1-1 makes these mutants a unique tool for further understanding auxin transport processes. 


\section{Methods}

\section{Plant material and chemicals}

Arabidopsis thaliana seeds were obtained from the Arabidopsis Biological Resource Center (ABRC), Ohio State University, Columbus, Ohio USA and the Nottingham Arabidopsis Stock Centre (NASC), University of Nottingham, Loughborough, Leicestershire UK. The following mutants were selected: N298: KOR1 - cellulose deficiency, [21,22], obtained from NASC; CS3074: aux1-7 - mutant auxin influx carrier, resistant to NAA and 2,4-D [40,41]; CS6201: ixr1-1 - IXB resistant [20], obtained from ABRC; and txr1-1 - TA resistant [15], kindly supplied by R. Loria (Cornell University, Cornell, USA). All except KOR1 have Columbia ecotype as a wild type (WT); the latter uses Wassilewkija ecotype. However, as no difference in TA responses between Columbia and Wassilewkija ecotypes was found (data not shown), only Columbia plants were used in other experiments.

TA was purified (> 98\% purity) from oatmeal broth cultures of Streptomyces scabiei (isolate G\#20) as previously described [42]. All other chemicals (including phytotoxins and hormones) were from Sigma-Aldrich Inc (St Lois, USA) unless otherwise stated. Key chemicals were dissolved in a range of solvents: TA, IXB and DCB -in methanol, IAA (Indole-3-acetic acid) and 2,4-D (2,4-Dichloro-phenoxyacetic acid) -in ethanol, NAA (1-Naphthalene acetic acid) and TIBA (2,3,5Triiodobenzoic acid) -in $\mathrm{NaOH}$, and NPA (Naptalam ${ }^{\circ}$ : N-1-Naphthylphtalamic acid) - in Dimethyl sulfoxide (DMSO). Working solutions contained $<0.025 \%$ of these solvents and control treatments always contained the equivalent concentration of the solvent.

\section{Root phytotoxin assays}

For all root experiments, plants were grown in a growth chamber at ambient temperature $22^{\circ} \pm 1^{\circ} \mathrm{C}$ and $16 \mathrm{~h}$ day length (light intensity $60 \mu \mathrm{mol} \mathrm{m} \mathrm{m}^{-2} \mathrm{~s}^{-1}$ ). A. thaliana seeds were surface-sterilised for $15 \mathrm{~min}$ in bleach solution (available Cl: $1.5 \% \mathrm{~m} / \mathrm{v}$ ). Twenty seeds were plated directly in two rows into Petri dishes containing Murashige and Skoog (MS) basal medium [43] supplemented with $8 \mathrm{~g} / \mathrm{L}$ agar and $10 \mathrm{~g} / \mathrm{L}$ sucrose. After a stratification period of 2 days at $4^{\circ} \mathrm{C}$, plates were transferred into the growth chamber and oriented in an upright position of about $85^{\circ}$, enabling roots to grow along the agar surface without penetrating it. After 5 days, plants were transferred to new plates containing the MS basal medium augmented with phytotoxin and/or auxin treatments, and the position of the tip of each root was marked on the plate. After a further 3 days of incubation root length was obtained by measuring the distance the root had grown beyond the marked point, and the effect of treatment on root growth was quantified.

\section{$\mathrm{CBI}$, auxin and auxin transport inhibitor screen}

Five lines of $A$. thaliana were selected for screening (WT, aux1-7, ixr1-1, KOR1 and txr1-1). Their root growth was examined on MS media augmented with (i) auxins - IAA, 2,4-D and NAA; (ii) the auxin transport inhibitors - NPA and TIBA; and (iii) the CBIs - DCB, IXB and TA. Each treatment had four replicates of five plants per plate $(n=20)$.

\section{Non-invasive ion flux measurements from A. thaliana roots}

Sterilised A. thaliana seeds were placed on $0.8 \%(\mathrm{w} / \mathrm{v})$ agar in $1.5 \mathrm{~mL}$ centrifuge tubes and stratified in the dark for $48 \mathrm{~h}$ at $4^{\circ} \mathrm{C}$. The bottom of the tubes was removed and the tubes were suspended over an aerated growth solution consisting of (macronutrients) $1.25 \mathrm{mM} \mathrm{KNO}_{3}$, $0.625 \mathrm{mM} \mathrm{KH}_{2} \mathrm{PO}_{4}, 0.5 \mathrm{mM} \mathrm{MgSO}, 0.5 \mathrm{mM} \mathrm{Ca}\left(\mathrm{NO}_{3}\right)_{2}$ and $0.045 \mathrm{mM}$ FeNaEDTA and (micronutrients) $0.16 \mu \mathrm{M} \mathrm{CuSO}_{4}, 0.38 \mu \mathrm{M} \mathrm{ZnSO}_{4}, 1.8 \mu \mathrm{M} \mathrm{MnSO}_{4}, 45 \mu \mathrm{M}$ $\mathrm{H}_{3} \mathrm{BO}_{3}, 0.015 \mu \mathrm{M}\left(\mathrm{NH}_{4}\right) 6 \mathrm{Mo}_{7} \mathrm{O}_{24}$, and $0.01 \mu \mathrm{M} \mathrm{CoCl}{ }_{2}$, adjusted to $\mathrm{pH}$ 5.6. The agar contained half-strength macronutrient concentrations with full strength micronutrients (pH 5.6). Genotypes (WT, ixr1-1 and txr1-1) were randomly arranged under constant light at room temperature, and nutrient solutions were changed every three days. Two treatments; a control $(0.025 \%$ DMSO) or $3 \mu \mathrm{M}$ NPA (containing DMSO at a concentration of approximately $0.025 \%$ ), were added to the growth medium of 11-day-old seedlings and the $\mathrm{pH}$ adjusted to 5.6.

Measurements of $\mathrm{H}^{+}$fluxes were made after $24 \mathrm{~h}$ of treatment using the non-invasive ion-selective microelectrode MIFE technique (ROCU, University of Tasmania, Hobart, Australia) as described previously [13,44]. Net ion fluxes were calculated using the MIFEFLUX software for cylindrical diffusion geometry [45]. Each 12-day-old seedling was placed in a $1 \mathrm{ml}$ Perspex measuring chamber containing $1 \mathrm{ml}$ of the Basic Salt Medium, BSM (in mM: $0.1 \mathrm{KCl}, 0.1 \mathrm{CaCl} 2$, pH 5.6 unbuffered, plus the respective treatment), $40 \mathrm{~min}$ prior to measurement. Net, steadystate ion fluxes were measured for $5 \mathrm{~min}$ from the mature and elongation zone $(1 \mathrm{~mm}$ and $100 \mu \mathrm{m}$ from the root tip, respectively). Due to the effects of the treatment solutions on the performance of the ion sensors, electrodes were calibrated in solutions containing the treatment solution for that particular measurement (i.e., DMSO \pm NPA), and new $\mathrm{H}^{+}$-selective electrodes were used for each seedling. Eight measurements were made for each treatment in both the elongation zone and the mature zone.

\section{Quantification of isoxaben and thaxtomin levels from A. thaliana roots}

Genotypes were essentially grown as described above for flux measurements in a hydroponic setup. The 6-day-old seedlings were transferred to four different treatment 
solutions: $1 \mu \mathrm{M}$ TA $\pm 3 \mu \mathrm{M}$ NPA; $100 \mathrm{nM}$ IXB $\pm 3 \mu \mathrm{M}$ NPA; with all treatments containing DMSO at a concentration of approximately $0.025 \%$ and a $\mathrm{pH}$ of 5.6 .

Plants were removed from treatment medium after $24 \mathrm{~h}$, with roots excised and rinsed six times in distilled water to remove treatment solutions. Five roots were pooled together per treatment solution and genotype. They were weighed, placed in a $1.5 \mathrm{~mL}$ Ependorf tube, mashed with an Ependorf pestle and $600 \mu \mathrm{L}$ of 30\% methanol was added. Ceramic beads $(0.5$ and $2.8 \mathrm{~mm})$ were added to the tubes with the tubes placed on a Vortex genie shaker for $10 \mathrm{~min}$, to ensure root tissue was thoroughly macerated to enable IXB or TA to move into the methanol solution. Tubes were centrifuged at 13000 rpm for 10 min with $200 \mu \mathrm{L}$ of the supernatant removed and stored at $4{ }^{\circ} \mathrm{C}$ prior to quantification. There were three replicates of each treatment combination.

Levels of TA and IXB were determined by UPLC-MS using a Waters Acquity $\mathrm{H}$-series UPLC coupled to a Waters Xevo triple quadrupole mass spectrometer. Injections were made onto a Waters Acquity UPLC C18 column $(2.1 \times 100 \mathrm{~mm} \times 1.7$ micron particles), with mobile phases $\mathrm{A}=1 \%$ acetic acid in water and $\mathrm{B}=$ acetonitrile. The column was held at $35^{\circ} \mathrm{C}$, the flow rate was $0.35 \mathrm{~mL} / \mathrm{min}$, and a linear gradient from $70 \% \mathrm{~A}, 30 \% \mathrm{~B}$ to $10 \% \mathrm{~A}, 90 \% \mathrm{~B}$ at 5 minutes was used, followed by a 3 minute re-equilibration between runs. Under these conditions TA eluted at $1.78 \mathrm{~min}$ and IXB at $4.28 \mathrm{~min}$. External calibration against standard solutions was used, with a QC run after every fifth sample. Injection volume was $35 \mathrm{uL}$ for thaxtomin samples and $10 \mathrm{uL}$ for IXB samples.

The mass spectrometer was operated in negative ion electrospray mode for TA and positive ion electrospray mode for IXB with a switch between modes at $2.4 \mathrm{~min}$. The 2 target compounds were detected by Multiple Reaction Monitoring (MRM), with channels $\mathrm{m} / z 437.15$ to 140.0 and $\mathrm{m} / z 437.15$ to 155.0 for TA (cone voltage $50 \mathrm{~V}$ for both channels, and collision energy $35 \mathrm{~V}$ and $27 \mathrm{~V}$ respectively), and $\mathrm{m} / \mathrm{z} 333.15$ to 150.0 and $\mathrm{m} / \mathrm{z} 333.15$ to 165.0 for IXB (cone voltage $27 \mathrm{~V}$ for both channels and collision energy $40 \mathrm{~V}$ and $23 \mathrm{~V}$ respectively). Dwell time was $145 \mathrm{~ms}$ per channel. The ion source temperature was $130^{\circ} \mathrm{C}$, the desolvation gas was nitrogen at $950 \mathrm{~L} / \mathrm{hr}$, the desolvation temperature was $450^{\circ} \mathrm{C}$ and the capillary voltage was $2.8 \mathrm{KV}$.

\section{Data analysis}

Data were subjected to analysis of variance using Genstat 11.1 (Rothamsted Experimental Station, Harpenden, Herfordshire, UK). Significance was calculated at either $\mathrm{P}=0.05$ or $\mathrm{P}=0.01$ as noted, and least significant difference (LSD) was used for comparison of treatment means. For root growth suppression data, the NLMIXED procedure in SAS (SAS/STAT, version 9.1, 2002-2003, SAS Institute Inc., Cary, NC, USA.) was used to fit the nonlinear model $Y=a *\left(b^{(\sqrt{ }(x)}\right)$ where ' $Y$ ' is the percentage modelled, ' $x$ ' is the measured variable (toxin concentration etc.), and ' $a$ ' and ' $b$ ' are parameters to be estimated for each genotype. The 'a' parameter corresponds to the maximum value reached at zero concentration, and ' $b$ ' controls the steepness of the fitted line. Comparisons of treatment effects were made by calculating the concentrations required to inhibit root growth (RG) to a $50 \%$ level, and these were compared between genotypes using F-tests; i.e. $\mathrm{RG}_{50}$. For MIFE ion flux data and quantification data, treatment means were separated using the $t$-test.

\section{Abbreviations}

CBI: Cellulose biosynthetic inhibitor; CesA: Cellulose synthase; DCB: Dichlobenil; 2,4-D: 2,4-dichloro-phenoxyacetic acid; DMSO: Dimethyl sulfoxide; IAA: Indole-3-acetic acid; IXB: Isoxaben; MS: Murashige and skoog; NAA: 1-naphthalene acetic acid; NPA: 1-napthylphthalamic acid; TA: Thaxtomin A; TIBA: 2,3,5-Triiodobenzoic acid; WT: Wild-type.

\section{Competing interests}

The authors declare that they have no competing interests.

\section{Authors' contributions}

RT participated in the study design, carried out the root inhibition assays, annotation and drafted the manuscript; SS participated in the design of the study and coordination; assisted with non-invasive ion flux measurements and help to draft the manuscript; TC carried out non-invasive ion flux measurements; ND developed detection methodology and carried out CBI quantification; CW conceived the study, participated in the design of the study and coordination and help to draft the manuscript. All authors read and approved the final manuscript.

\section{Acknowledgments}

For assistance with statistical analyses we thank D. Ratkowsky and R. Corkrey. This work was supported by a postgraduate scholarship award from the University of Tasmania (to RT), a grant from Horticulture Australia Limited (HAL) funded in partnership with the Potato Processing Association of Australia and the Australian Government (to CW), and a grant from the Australian Research Council (to SS).

\section{Author details}

${ }^{1}$ Tasmanian Institute of Agriculture (TIA), University of Tasmania (UTAS), 13 St John's Ave, New Town, Tasmania 7008, Australia. ${ }^{2}$ TIA, UTAS, Private Bag 54, Hobart, Tasmania TAS 7001, Australia. ${ }^{3}$ Central Science Laboratory, University of Tasmania, Private Bag 74, Hobart, Tasmania 7001, Australia.

Received: 19 October 2012 Accepted: 30 April 2013 Published: 3 May 2013

\section{References}

1. Loria R, Kers J, Joshi M: Evolution of plant pathogenicity in Streptomyces. Ann Rev Phytopathol 2006, 44:469-487.

2. Kers JA, Cameron KD, Joshi MV, Bukhalid RA, Morello JE, Wach MJ, Gibson DM, Loria R: A large, mobile pathogenicity island confers plant pathogenicity on Streptomyces species. Mol Microbiol 2005, 55:1025-1033.

3. King RR, Lawrence CH, Clark MC, Calhoun LA: Isolation and characterisation of phytotoxins associated with Streptomyces scabies. J Chem Soc Chem Commun 1989, 13:849-850.

4. Lawrence CH, Clark MC, King RR: Induction of common scab symptoms in aseptically cultured potato tubers by the vivotoxin, thaxtomin. Phytopathology 1990, 80:606-608.

5. King R, Lawrence C, Gray J: Herbicidal properties of the thaxtomin group of phytotoxins. J Agric Food Chem 2001, 49:2298-2301.

6. Brochu V, Girard-Martel M, Duval I, Lerat S, Grondin G, Domingue O, Beaulieu C, Beaudoin N: Habituation to thaxtomin A in hybrid poplar cell 
suspensions provides enhanced and durable resistance to inhibitors of cellulose synthesis. BMC Plant Biology 2010, 10:272.

7. Bischoff V, Cookson SJ, WU S, Scheible WR: Thaxtomin A affects CESAcomplex density, expression of cell wall genes, cell wall composition, and causes ectopic lignification in Arabidopsis thaliana seedlings. J Exp Bot 2009, 60:955-965.

8. Desprez T, Vernhettes S, Fagard M, Refregier G, Desnos T, Aletti E, Py N, Pelletier S, Hofte $\mathrm{H}$ : Resistance against herbicide isoxaben and cellulose deficiency caused by distinct mutations in same cellulose synthase isoform CESA6. Plant Physiol 2002, 128:482-490.

9. Scheible WR, Eshed R, Richmond T, Delmer D, Somerville C: Modifications of cellulose synthase confer resistance to isoxaben and thiazolidinone herbicides in Arabidopsis ixr1 mutants. Proc Natl Acad Sci USA 2001, 98:10079-10084.

10. Melida H, Encina A, Alvarez J, Luis Acebes J, Caparros-Ruiz D: Unraveling the biochemical and molecular networks involved in maize cell habituation to the cellulose biosynthesis inhibitor dichlobenil. Mol Plant 2010, 3:842-853

11. Nakagawa $N$, Sakurai N: Increase in the amount of celA1 protein in tobacco BY-2 cells by a cellulose biosynthesis inhibitor, 2,6-dichlorobenzonitrile. Plant Cell Physiol 1998, 39:779-785.

12. Duval I, Beaudoin N: Transcriptional profiling in response to inhibition of cellulose synthesis by thaxtomin A and isoxaben in Arabidopsis thaliana suspension cells. Plant Cell Rep 2009, 28:811-830.

13. Tegg RS, Melian L, Wilson CR, Shabala S: Plant cell growth and ion flux responses to the streptomycete phytotoxin thaxtomin $\mathrm{A}$ : calcium and hydrogen flux patterns revealed by the non-invasive MIFE technique. Plant Cell Physiol 2005, 46:638-648.

14. Duval I, Brochu V, Simard M, Beaulieu C, Beaudoin N: Thaxtomin A induces programmed cell death in Arabidopsis thaliana suspension-cultured cells. Planta 2005, 222:820-831.

15. Scheible WR, Fry B, Kochevenko A, Schindelasch D, Zimmerli L, Somerville S, Loria R, Somerville CR: An Arabidopsis mutant resistant to thaxtomin A, a cellulose synthesis inhibitor from Streptomyces species. Plant Cell 2003, 15:1781-1794

16. Tegg RS, Corkrey R, Wilson CR: Relationship between the application of foliar chemicals to reduce common scab disease of potato and correlation with thaxtomin A toxicity. Plant Dis 2012, 96:97-103.

17. Tegg RS, Gill WM, Thompson HK, Davies NW, Ross JJ, Wilson CR: Auxin-induced resistance to common scab disease of potato linked to inhibition of thaxtomin A toxicity. Plant Dis 2008, 92:1321-1328.

18. Mclntosh $A H$, Chamberlain $K$, Dawson GW: Foliar sprays against potato common scab: compounds related to 3,5-dichlorophenoxyacetic acid. Crop Prot 1985, 4:473-480.

19. Shapiro AD: Using Arabidopsis mutants to delineate disease resistance signaling pathways. Can J Plant Pathol 2000, 22:199-216.

20. Heim DR, Roberts JL, Pike PD, Larrinua IM: Mutation of a locus of Arabidopsis thaliana confers resistance to the herbicide isoxaben. Plant Physiol 1989, 90:146-150.

21. Nicol F, His I, Jauneau A, Vernhettes S, Canut H, Hofte H: A plasma membrane-bound putative endo-1,4-beta-D-glucanase is required for normal wall assembly and cell elongation in Arabidopsis. EMBO J 1998, 17:5563-5576.

22. Zuo JR, Niu QW, Nishizawa N, Wu Y, Kost B, Chua NH: KORRIGAN, an Arabidopsis endo-1,4-beta-glucanase, localizes to the cell plate by polarized targeting and is essential for cytokinesis. Plant Cell 2000, 12:1137-1152.

23. Yamamoto M, Yamamoto KT: Differential effects of 1-naphthaleneacetic acid, indole-3-acetic acid and 2,4-dichlorophenoxyacetic acid on the gravitropic response of roots in an auxin-resistant mutant of Arabidopsis, aux1. Plant Cell Physiol 1998, 39:660-664.

24. Fry $B$, Loria R: Thaxtomin A: evidence for a plant cell wall target. Physiol Mol Plant Pathol 2002, 60:1-8.

25. Errakhi R, Dauphin A, Meimoun P, Lehner A, Reboutier D, Vatsa P, Briand J, Madiona K, Rona JP, Barakate M, Wendehenne D, Beaulieu C, Bouteau F: An early $\mathrm{Ca}^{2+}$ influx is a prerequisite to thaxtomin A-induced cell death in Arabidopsis thaliana cells. J Exp Bot 2008, 59:4259-4270.

26. Paredez AR, Somerville CR, Ehrhardt DW: Visualization of cellulose synthase demonstrates functional association with microtubules. Science 2006, 312:1491-1495.
27. Sato S, Kato T, Kakegawa K, Ishii T, Liu YG, Awano T, Takabe K, Nishiyama Y, Kuga S, Nakamura Y, Tabata S, Shibata D: Role of the putative membranebound endo-1,4-beta-glucanase KORRIGAN in cell elongation and cellulose synthesis in Arabidopsis thaliana. Plant Cell Physiol 2001, 42:251-263

28. Lee $\mathrm{SH}$, Cho HT: PINOID positively regulates auxin efflux in Arabidopsis root hair cells and tobacco cells. Plant Cell 2006, 18:1604-1616.

29. Friml J, Palme K: Polar auxin transport - old questions and new concepts? Plant Mol Biol 2002, 49:273-284

30. Lomax T, Muday G, Rubery P: Auxin transport. In Plant hormones: physiology, biochemistry, and molecular biology. 2nd edition. Edited by Davies P. Dordrecht, Netherlands: Kluwer Academic Publishers; 1995:509-530.

31. Cooke T, Poli D, Sztein A, Cohen J: Evolutionary patterns in auxin action. Plant Mol Biol 2002, 49:319-338.

32. Peer WA, Blakeslee JJ, Yang H, Murphy AS: Seven things we think we know about auxin transport. Molecular Plant 2011, 4:487-504.

33. Petrasek J, Friml J: Auxin transport routes in plant development. Development 2009, 136:2675-2688.

34. Zazimalova E, Murphy AS, Yang H, Hoyerova K, Hosek P: Auxin transporters why so many? Cold Spring Harb Perspect Bio/ 2010, 2:a001552

35. Peer WA, Bandyopadhyay A, Blakeslee JJ, Makam SI, Chen RJ, Masson PH, Murphy AS: Variation in expression and protein localization of the PIN family of auxin efflux facilitator proteins in flavonoid mutants with altered auxin transport in Arabidopsis thaliana. Plant Cell 2004, 16:1898-1911.

36. Sieberer T, Leyser O: Auxin transport, but in which direction. Science 2006, 312:858-860.

37. Veraestrella R, Barkla BJ, Higgins VJ, Blumwald E: Plant defense response to fungal pathogens - activation of host-plasma membrane $\mathrm{H}^{+}$-ATPase by elicitor-induced enzyme dephosphorylation. Plant Physiol 1994, 104:209-215.

38. Petersson SV, Johansson Al, Kowalczyk M, Makoveychuk A, Wang JY, Moritz T, Grebe M, Benfey PN, Sandberg G, Ljung K: An auxin gradient and maximum in the Arabidopsis root apex shown by high-resolution cell-specific analysis of IAA distribution and synthesis. Plant Cell 2009, 21:1659-1668.

39. Sharples KR, Hawkes TR, Mitchell G, Edwards LS, Langford MP, Langton DW, Rogers KM, Townson JK, Wang YL: A novel thiazolidinone herbicide is a potent inhibitor of glucose incorporation into cell wall material. Pestic Sci 1998, 54:368-376.

40. Bennett MJ, Marchant A, Green HG, May ST, Ward SP, Millner PA, Walker AR, Schulz B, Feldmann KA: Arabidopsis AUX1 gene: A permease-like regulator of root gravitropism. Science 1996, 273:948-950.

41. Swarup R, Kargul J, Marchant A, Zadik D, Rahman A, Mills R, Yemm A, May S, Williams L, Millner P, Tsurumi S, Moore I, Napier R, Kerr ID, Bennett MJ: Structure-function analysis of the presumptive Arabidopsis auxin permease AUX1. Plant Cell 2004, 16:3069-3083.

42. Wilson CR, Luckman GA, Tegg RS, Yuan ZQ, Wilson AJ, Eyles A, Conner AJ: Enhanced resistance to common scab of potato through somatic cell selection in cv. Iwa with the phytotoxin thaxtomin A. Plant Pathol 2009, 58:137-144.

43. Murashige T, Skoog F: A revised medium for rapid growth and bioassays with tobacco tissue cultures. Physiol Plantarum 1962, 15:473-497.

44. Shabala S, Cuin TA, Prismall L, Nemchinov LG: Expression of animal CED-9 anti-apoptotic gene in tobacco modifies plasma membrane ion fluxes in response to salinity and oxidative stress. Planta 2007, 227:189-197.

45. Shabala L, Ross T, McMeekin T, Shabala S: Non-invasive microelectrode ion flux measurements to study adaptive responses of microorganisms to the environment. FEMS Microbiol Rev 2006, 30:472-486.

\section{doi:10.1186/1471-2229-13-76}

Cite this article as: Tegg et al:: Enhanced resistance to the cellulose biosynthetic inhibitors, thaxtomin A and isoxaben in Arabidopsis thaliana mutants, also provides specific co-resistance to the auxin transport inhibitor, 1-NPA. BMC Plant Biology 2013 13:76. 